\title{
PENGARUH BRAND LOYALTY, WORD OF MOUTH, DAN CELEBRITY ENDORSEMENT TERHADAP REPURCHASE INTENTION
}

\author{
Leonardo Charles Ferdinands \\ Program Studi Magister Manajemen Universitas Tarumanagara \\ leonardocharlesf@gmail.com
}

\begin{abstract}
Repurchase intention is something that must be noticed by companies that provide products or services. Due to the repurchase intention of a customer, the sales level of a product or service will continue and the company will get its sales again. The purpose of this study was to determine the effect of brand loyalty, word of mouth and celebrity endorsement on repurchase intention, one of the sports product brands. The research method that been used in this study is multiple linear regression and data collection techniques used are using questionnaires distributed online through help from Google Form. The population and sample in this study were all people who knew and had bought a product from one of the sports brands, and the total number of respondents collected was 150 people. The results of this study are that brand loyalty, word of mouth and celebrity endorsement have a positive influence on repurchase intention.
\end{abstract}

Abstrak : Repurchase intention merupakan suatu hal yang harus diperhatikan oleh perusahaan yang menyediakan produk atau jasa. Dikarenakan dengan adanya repurchase intention dari seorang pelanggan, maka tingkat penjualan akan suatu produk atau jasa tersebut akan terus berlangsung dan perusahaan akan mendapatkan salesnya lagi. Tujuan dilakukannya penelitian ini adalah untuk mengetahui pengaruh brand loyalty, word of mouth dan celebrity endorsement terhadap repurchase intention salah satu brand produk olahraga. Metode penelitian yang digunakan dalam penelitian ini adalah regesi liner berganda dan teknik pengumpulan data yang digunakan adalah dengan menggunakan media kuesioner yang disebar secara online melalui bantuan dari google form. Yang menjadi populasi dan sampel dalam penelitian ini adalah seluruh orang yang mengetahui dan pernah membeli produk salah satu brand olahraga, dan total responden yang berhasil dikumpulkan adalah 150 orang. Hasil dari penelitian ini adalah brand loyalty, word of mouth dan celebrity endorsement memiliki pengaruh positif terhadap repurchase intention.

Keywords: Repurchase Intention, Brand Loyalty, Word Of Mouth, Celebrity Endorsement

\section{PENDAHULUAN}

Seiring berkembangnya jaman, inovasi yang dilakukan oleh suatu perusahaan terhadap produk yang dijualnya terus dilakukan. Tujuannya antara lain adalah untuk mengungguli kompetitor dan memenagkan persaingan dalam pasar. Namun rasanya inovasi dalam produk saja tetaplah tidak cukup, bagi suatu perusahaan untuk memenangkan persaingan dengan kompetitor kompetitornya. Begitu juga dalam industri perlengkapan olah raga, pada saat ini perlengkapan olahraga bukan unsur kenyamanan saja yang diperhatikan namun dari sisi modis juga dilihat. Maka dari itu selain peningkatan kualitas dan inovasi yang dilakukan kepada produk dari suatau perusahaan, dibutuhkan juga strategi marketing yang benar dan efektif dalam memenangkan kompetisi ini. Salah satu faktor yang perlu diperhatikan adalah repurchase intention yang akan menjadi salah satu variabel yang diteliti dalam penelitian ini. Repurchase intention memiliki peran penting dalam suatu perusahaan, karena dengan adanya repurchase intention pelanggan dapat melakukan pembelian kembali terhadap suatu produk atau jasa dari perusahaan yang sama. Dengan adanya pembelian 
kembali tersebut maka akan menghasilkan sales yang tentunya menambah pendapatan perusahaan. Repurchase intention sendiri di definisikan sebagai perilaku aktual konsumen yang menghasilkan pembelian terhadap suatu produk atau layanan yang sama lebih dari satu kali (Peyrot \& Van Doren, 1994).

Pada penelitian ini brand loyalty, word of mouth dan celebrity endorsement yang akan diteliti apakah akan memberikan pengaruh terhadap repurchase intention. Brand loyalty adalah respon perilaku pembelian yang di ekspresikan dari waktu ke waktu oleh beberapa unit pengambilan keputusan berhubungan dengan satu atau lebih merek tertentu (Chestnut \& Jacoby, 1978). Word of mouth adalah komunikasi antarpribadi yang terjadi antara satu individu dengan yang lainnya berdasarkan pengalaman yang dimiliki oleh masing masing individu kepada suatu perusahaan atau produk dalam bentuk barang ataupun jasa (Silverman, 2001). Celebrity Endorsement dapat didefinisikan sebagai setiap individu yang dikenali secara umum di publik dan menggunakan ketenarannya untuk mewakilkan suatu produk atau jasa dalam sebuah iklan (McCracken, 1989). Hasil dari penelitian ini akan dibandingkan dengan penelitian sebelumnya yang dilakukan oleh Habib \& Aslam (2014) yang membahas tentang pengaruh dari brand loyalty terhadap repurchase intention, Moslehpour, Wong, Van Pham \& Aulia (2017) yang meneliti tentang seberapa besar pengaruh word of mouth dibandingkan dengan variabel lain terhadap repurchase intention dan juga penelitian yang dilakukan oleh Khan, Rukhsar \& Shoaib (2016) yang meneliti tentang pengaruh celebrity endorsement terhadap repurchase intention dan keputusan pembelian dari suatu produk.

\section{TINJAUAN PUSTAKA}

\section{Repurchase Intention}

Repurchase di definisikan sebagai perilaku aktual konsumen yang menghasilkan pembelian terhadap suatu produk atau layanan yang sama lebih dari satu kali (Peyrot \& Van Doren, 1994). Repurchase intention didefinisikan sebagai keputusan pelanggan untuk terlibat dalam aktifitas pembelian di masa depan terhadap penjual (Hume, Mort \& Winzar, 2007).

\section{Brand Loyalty}

Brand loyalty adalah respon perilaku pembelian yang di ekspresikan dari waktu ke waktu oleh beberapa unit pengambilan keputusan berhubungan dengan satu atau lebih merek tertentu (Chestnut \& Jacoby, 1978). Brand loyalty didorong oleh kepuasan pelanggan, dan kesetiaan terhadap suatu merek mencerminkan probabilitas sang pelanggang akan memilih merek itu kembali di masa yang akan dating (Prus \& Brand, 1995).

\section{Word of Mouth}

Word of mouth adalah komunikasi antarpribadi yang terjadi antara satu individu dengan yang lainnya berdasarkan pengalaman yang dimiliki oleh masing masing individu kepada suatu perusahaan atau produk dalam bentuk barang ataupun jasa (Silverman, 2001). Komunikasi word of mouth adalah proses komunikasi untuk penyediaan saran, baik secara individu atau dalam kelompok tentang suatu produk atau jasa yang bertunjuan untuk memberikan informasi tentang pengalaman pribadinya tentang produk atau jasa tersebut (Kotler \& Keller, 2007).

\section{Celebrity Endorsement}

Celebrity Endorsement dapat didefinisikan sebagai setiap individu yang dikenali secara umum di publik dan menggunakan ketenarannya untuk mewakilkan suatu produk atau jasa dalam sebuah iklan (McCracken, 1989). Selain itu, dijelaskan juga bahwa dukungan dari celebrity memberikan dampak kepada efektivitas periklanan, brand awareness, brand recall, buying intentions, dan buying behavior (Spry, Pappu, \& Cornwell, 2011). 


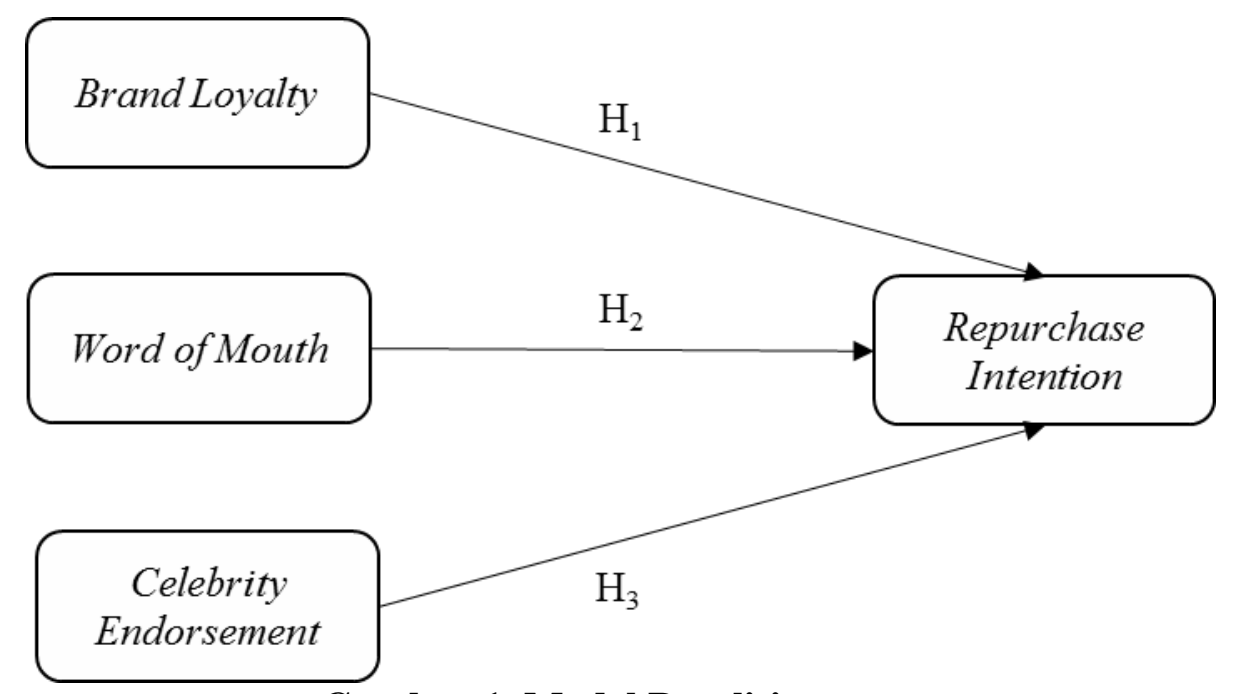

Gambar 1. Model Penelitian

\section{Pengembangan Hipotesis}

Kaitan antaran brand loyalty dan repurchase intention

Menurut Habib \& Aslam (2014) brand loyalty memberikan dampak yang positif terhadap repurchase intention. Anderson \& Sullivan (1990) menyatakan bahwa loyalitas dari seorang konsumen memiliki hubungan positif terhadap repurchase intention. Menurut Feng \& Yanru (2013) brand loyalty memiliki dampak yang positif terhadap repurchase intention. Sehingga dapat disimpulkan bahwa brand loyalty memiliki pengaruh positif terhadap repurchase intention. Berdasarkan uraian di atas, maka hipotesis penelitian adalah:

$\mathrm{H} 1$ : Brand loyalty berpengaruh positif terhadap repurchase intention salah satu produk brand olahraga.

\section{Kaitan antaran word of mouth dan repurchase intention}

Menurut Moslehpour, Wong, Van Pham \& Aulia (2017) word of mouth memiliki pengaruh yang lebih besar dibandingkan dengan perceived price dan country of origin. Menurut Leonnard \& Thung (2017) word of mouth memiliki hubungan yang positif dengan repurchase intention. Sehingga dapat disimpulkan bahwa word of mouth memiliki pengaruh positif terhadap repurchase intention. Berdasarkan uraian di atas, maka hipotesis penelitian adalah:

$\mathrm{H}$ 2: Word of mouth berpengaruh positif terhadap repurchase intention salah satu produk brand olahraga.

\section{Kaitan antaran celebrity endorsement dan repurchase intention}

Menurut Khan, Rukhsar \& Shoaib (2016) celebrity endorsement memberikan dampak yang positif terhadap keputusan pembelian seseorang dan untuk melakukan pembelian yang berulan terhadap suatu produk atau jasa yang sama. Hermawan \& Semuel (2017) juga menyatakan bahwa celebrity endorsement memiliki pengaruh yang positif terhadap repurchase intention diikuti dengan membangun brand image terhadap suatu produk atau jasa tersebut. Sehingga dapat disimpulkan bahwa celebrity endorsement memiliki dampak yang positif terhadap repurchase intention. Berdasarkan uraian di atas, maka hipotesis penelitian adalah: 
H3: Celebrity endorsement berpengaruh positif terhadap repurchase intention salah satu produk brand olahraga.

\section{METODE PENELITIAN}

Pada penelitian ini, jenis penelitian yang digunakan dalam penelitian ini adalah deskriptif dengan pendekatan kuantitatif. Periode penelitian dimulai pada bulan January hingga Desember 2018. Data yang digunakan dalam penelitian ini adalah data primer yang menggunakan media kuesioner untuk melakukan pengumpulan data. Kuesioner tersebut disebarkan secara online menggunakan bantuan media google form. Jumlah sample yang digunakan dalam penelitian ini adalah 155 yang sudah sesuai dengan kriteria penelitian.

Tabel 1. Variabel dan Pengukuran

\begin{tabular}{|l|c|l|}
\hline \multicolumn{1}{|c|}{ Variabel } & \multicolumn{1}{c|}{ Item } & \multicolumn{1}{c|}{ Sumber } \\
\hline Brand Loyalty $(\mathrm{X} 1)$ & 4 & Ji Feng \& He Yanru (2013) \\
\hline Word of Mouth $(\mathrm{X} 2)$ & 4 & Senecal \& Nantel (2004) \\
\hline Celebrity Endorsement (X3) & 5 & Poghosyan (2015) \\
\hline Repurchase Intention (Y) & 4 & Hellier (2003) \\
\hline
\end{tabular}

Untuk mengukur variabel penelitian, beberapa instrument di adaptasi dari penelitian sebelumnya. Pada tabel 1. Ditunjukkan bahwa pengukuran masing masing variabel dan sumbernya. Hasil dari analisis validitas yang dilakukan, menunjukkan bahwahasil corrected item total correlation berkisar dari 0,334 hingga 0,722. Karena nilai corrected item total correlation lebih besar dari 0,157 maka dapat disimpulkan bahwa seluruh butir pertanyaan dalam instrument adalah valid. Begitu juga hasil dari uji reliabilities yang dilakukan, menunjukkan bahwa crobnach's alpha berkisar 0,709 hingga 0,824 . Sehingga dapat disimpulkan bahwa variabel dalam penelitian ini reliabel dikarenakan memiliki nilai koefisien cronbach's alpha melebihi 0,6. Uji asumsi sepertu uji normalitas, multikolinearitas dan heteroskedastistas telah dilakukan dan hasilnya menunjukkan seuluruh uji asumsi terpenuhi. Taraf signifikansi yang digunakan dalam penelitian ini adalah $5 \%$.

\section{HASIL DAN PEMBAHASAN}

Hair, et al. (2006) menyatakan bahwa jika $\mathrm{r}$ hitung > $\mathrm{r}$ tabel . maka pertanyaan tersebut dinyatakan valid. Nilai $\mathrm{r}$ tabel dalam peneilitian ini dengan $\mathrm{df}=153$ dan menggunakan nilai signifikansi $\alpha 0,05$ adalah 0,157 . Setelah dilakukan uji, seluruh nilai $\mathrm{r}$ hitung dari pertanyaan pertanyaan yang mewakilkan variabel yang ada lebih besar dibandingkan dengan $\mathrm{r}$ tabel. Maka dari itu dapat disimpulkan bahwa seluruh pertanyaan pertanyaan dalam penelitian ini adalah valid. Uji reliabilitas juga dilakukan dengan menggunakan indikator cronbach alpha harus lebih besar dari 0,6. Dan hasil dari uji reliabilitas adalah seluruh variabel memeiliki cronbach alpha yang lebih besar dari 0,6 dan dapat disimpulkan bahwa seluruh variabel lolos dalam uji ini dan dapat dikatan reliabel.

Tabel 2. Hasil Pengujian Hipotesis

\begin{tabular}{|l|l|l|l|}
\hline \multicolumn{2}{|c|}{ Hipotesis } & \multicolumn{1}{c|}{ Hasil } & \multicolumn{1}{c|}{ t-Hitung } \\
\hline H1 & BL - RI & Didukung & 5,958 \\
\hline H2 & WOM - RI & Didukung & 2,476 \\
\hline H3 & CE - RI & Didukung & 2,664 \\
\hline
\end{tabular}

Keterangan tabel: $\mathrm{BL}=$ brand loyalty, $\mathrm{WOM}=$ word of mouth, $\mathrm{CE}=$ celebrity endorsement \& $\mathrm{RI}=$ repurchase intention

Tabel 2 menunjukkan hasil dari uji t, nilai hipotesis akan diterima apabila nilai dari t-hitung lebih besar dari 1,96. Dari tabel tersebut dapat disimpulkan bahwa seluruh 
hipotesis diterima dikarenakan melebihi batas minimal dari t-hitung.Jika dibandingkan antara hasil dari $\mathrm{H} 1$ dengan penelitian sebelumnya yang dilakukan oleh Habib \& Aslam (2014), brand loyalty memiliki pengaruh yang positif terhadap repurchase intention. Dalam penelitian ini dijelaskan bahwa yang membangun brand loyalty adalah kepuasan dari konsumen terhadap suatu merek terentu sehingga membangun rasa percaya terhadap merek tersebut dan dapat menciptakan loyalitas dan membangun repurchase intention. Maka dari itu pelanggan dari salah satu produk brand olahraga yang memiliki brand loyalty, memiliki peluang besar untuk melakukan repurchase terhadap salah satu produk brand olahraga. Dikarenakan pelanggan tersebut sudah merasa loyal dan memiliki rasa percaya terhadap merek tersebut.

Sementara itu untuk H2 dibandingkan dengan penelitian sebelumnya yang dilakukan oleh Moslehpour, Wong, Van Pham \& Aulia (2017), word of mouth memiliki pengaruh yang positif terhadap repurchase intention. Dalam penelitian ini variabel yang diteliti antara lain adalah word of mouth, country of origin dan perceived price, hasil dari penelitian ini adalah word of mouth menjadi variabel yang paling besar memberikan pengaruh terhadap repurchase intention dibandingkan dengan country of origin dan perceived price. Word of mouth dapat tercipta dari konsumen yang merasa puas terhadap suatu produk atau iklan yang memberikan kesan ke publik, lalu berita dari produk tersebut akan menjadi topik untuk pembicaraan ke orang lain. Salah satu produk brand olahraga harus selalu memberikan iklan yang menarik dan memberikan produk yang berkualitas, sehingga word of mouth dapat tercipta dan mendorong para pelanggan untuk melakukan repurchase. Dan yang terakhir, hasil dari H3 akan dibandingkan dengan penelitian sebelumnya yang dilakukan oleh Khan, Rukhsar \& Shoaib (2016). Di dalam penelitiannya, celebrity endorsement memiliki pengaruh terhadap keputusan pelanggan untuk melakukan repurchase intention terhadap suatu produk. Dalam penelitian ini celebrity endorsement dapat membantu dalam membangun brand image dan brand trust terhadap suatu produk atau jasa yang di iklankan. Selain itu juga dapat menarik perhatian para pelanggan yang sudah pernah membeli ataupun yang belum sama sekali. Produk brand olah raga harus memilih celebrity yang memiliki prestasi dan reputasi yang baik, sehingga dapat memberikan kesan yang positif juga dan dapat dijadikan role model oleh masyarakat. Dengan ada image dari celebrity ini rasa percaya terhadap kualitas produk dari brand olahraga dapat terbangun di benak masyarakat dan pelanggan. Prestasi dari celebrity yang di endorse juga menunjukkan bahwa kualitas dari produk suatu brand olah raga memiliki kualitas yang sangat baik. Sehingga dengan celebrity endorsement yang tepat, dapat membangun repurchase intention terhadap produk dari suatu brand olahraga tersebut.

\section{KESIMPULAN DAN SARAN}

Kesimpulan yang dapat ditarik dari penelitian ini adalah, brand loyalty, word of mouth, dan celebrity endorsement memiliki pengaruh yang positif terhadap repurchase intention. Maka dari itu suatu brand olahraga, perlu sekali menjaga customer loyalty yang dimiliki oleh pelanggan pelanggannya. Dan brand olahraga tersebut harus membagun brand trust yang baik, bagi calon pelanggan dari salah satu brand olahraga. Dikarenakan bila trust dari pelanggang sudah terbangun dan pelanggan tersebut merasa puas akan produk atau jasa yang diberikan oleh, lama kelamaan pelanggan tersebut akan menjadi loyal terhadap salah satu brand produk olahraga dan dapat mempengaruhi untuk melakukan repurchase. Selain itu suatu brand olahraga juga perlu membuat iklan yang menarik dan memberikan kualitas produk yang sangat baik, dengan tujuan menciptakan positive word of mouth kepada pelanggan. Dengan adanya word of mouth ini, pelanggan suatu brand olahraga dapat menceritakan tentang kualitas dan pengalamannya ataupun iklan dari suatu brand olahraga 
yang menarik kepada orang orang terdekatnya yang nantinya dapat mengarah ke repurchase ataupun purchase terhadap produk brand olahraga tersebut . Begitu juga dengan celebrity yang akan dipilih oleh suatu brand olahraga untuk tampil dalam iklannya. agar celebrity endorsement dapat berjalan dengan efektif dan efisien, suatu brand olahraga harus memilih celebrity yang memiliki prestasi dan reputasi baik untuk mewakilkan brand olahraga tersebut dalam menyampaikan pesannya ke masyarakat. Karena celebrity ini nantinya akan menjadi role model bagi masyarakat dan perwakilan dari brand olahraga tersebut.

\section{DAFTAR PUSTAKA}

Habib, S. \& Aslam, S. (2014). Influence of Brand Loyalty on Consumer Repurchase Intentions of Coca-Cola, European Journal of Business and Management

Feng, J. \& Yanru, H. (2013). Study on the Relationships Among Customers Satisfaction, Brand Loyalty and Repurchase Intention, Journal of Theoritical and Applied Information Technology, 49, 180-186.

Khan, S. K., Rukhsar, A. \& Shoaib, M. (2016). Influence of Celebrity Endorsement on Consumer Repurchase Intention, Journal of Business and Management, 18, 612.

Hermawan, Y. \& Semuel, H. (2017). Analisa Pengaruh Celebrity Endosement Lee Min Ho Dalam Iklan Luwak White Koffie Terhadap Brand Image dan Repurchase Intention, International Journal of Research in IT, Management and Engineering, 5(4), 1-31.

Ercis, A., Unal, S., Candan, F. B. \& Yildrim, H. (2012). The Effect of Brand Satisfaction, Trust, and Brand Commitment on Brand Loyalty and Repurchase Intentions, Procedia - Social and Behavioral Sciences, 58, 1395-1404.

Leonnard \& Thung, F. (2017). The Relationship of Service Quality, Word of Mouth, and Repurchase Intention in Online Transportation Services, Journal of Process Management, 5, 30-40.

Moslehpour, M., Wong, W. Van Pham, K. \& Aulia C. K. (2017). Repurchase Intention of Korean Beauty Products Among Taiwanese Consumers, Asia Pacific, Journal of Marketing and Logistics, 29, 569-588.

Peyrot, M. \& Doris, V. D. (1994). Effect of a Class Action Suit on Consumer Repurchase Intentions. The Journal of Consumer Affairs. 28, 361-379.

Chestnut, R. W. \& Jacoby, J. (1978). Brand Loyalty: Measurement and Management. John Wiley and Sons, New York, 1978.

Silverman, G. (2001). The secrets of word-of-mouth marketing: how to trigger exponential sales through runaway word-of-mouth. New York: Amacom.

McCracken, G. (1989). Who is the Celebrity Endorser? Cultural Foundations of the Endorsement Process. Journal of Consumer Research. 16, 310-321.

Prus, A \& Brandt, B. D. (1995), Understanding Your Customers,Marketing Tolls, Vol. 2, No. 5, 10-14.

Hume, M., Mort, G. S. \& Winzar, H. (2006). Exploring Repurchase Intention in a Performing Arts Context: Who Comes? and Why Do They Come back?, International Journal of Nonprofit and Voluntary Sector Marketing, 12, 135-148.

Kotler, P. \& Keller K. L. (2007), Marketing Management, Volume 1, Edition 12.

Spry, A., Pappu, R. \& Cornwell, T. B. (2011), Celebrity Endorsement, Brand Credibility and Brand Equity, European Journal of Marketing, 45, 
